\title{
How do Emotions Influence Brand Attachment? The Mediation Role of Brand Authenticity: An Abstract
}

\author{
Yousra Hallem, Wissal Ben Arfi, and Haithem Guizani
}

\begin{abstract}
In time of uncertainty, brand authenticity is seen as one of the major factors of brand success. Both academics and practitioners have come to the conclusion that brand authenticity has become an essential trait of the brand in times when consumers are overwhelmed with product offerings.

This research examines the impact of emotions on brand attachment by studying the mediating role of perceived brand authenticity. In-store emotions and consumption emotions have been taken into consideration.

A multifaceted conceptualization of perceived brand authenticity has been considered with continuity, credibility, integrity, and symbolism dimensions. A study was conducted on 349 consumers of a chocolate brand. Empirical results show the existence of a total mediating effect of perceived brand authenticity in the relationship between consumption emotions and brand attachment.

This effect is reached through the mediation of credibility, integrity, and continuity dimensions. For in-store emotions, only the symbolic dimension has a partial mediating effect. The findings of this research are discussed, and implications for marketing theory and for managers are recommended.
\end{abstract}

References Available Upon Request

\footnotetext{
Y. Hallem $(\bowtie) \cdot$ W. B. Arfi

IDRAC Business School, Lyon, France

e-mail: yousra.hallem@idraclyon.com; wissal.benarfi@idraclyon.com

H. Guizani

Sciences Po, Grenoble, France

e-mail: haithem.guizani@sciencespo-grenoble.fr 